\title{
BMJ Open Non-prescription antibiotic use for cough among Chinese children under 5 years of age: a community-based cross- sectional study
}

\author{
Yao Zhu (D) , ${ }^{1}$ Xuewen Tang, ${ }^{1}$ Rui Yan, ${ }^{1}$ Zhujun Shao, ${ }^{2}$ Yang Zhou, ${ }^{1}$ Xuan Deng, \\ Shuying Luo, ${ }^{3}$ Hanqing $\mathrm{He}^{1}$
}

To cite: Zhu Y, Tang X, Yan R, et al. Non-prescription antibiotic use for cough among Chinese children under 5 years of age: a community-based crosssectional study. BMJ Open 2021;11:e051372. doi:10.1136/ bmjopen-2021-051372

- Prepublication history and additional supplemental material for this paper are available online. To view these files, please visit the journal online (http://dx.doi.org/10.1136/ bmjopen-2021-051372)

$\mathrm{YZ}$ and $\mathrm{XT}$ contributed equally.

Received 18 March 2021 Accepted 23 November 2021

Check for updates

C Author(s) (or their employer(s)) 2021. Re-use permitted under CC BY-NC. No commercial re-use. See rights and permissions. Published by BMJ.

1Department of Immunization Program, Zhejiang Provincial Center for Disease Control and Prevention, Hangzhou, China ${ }^{2}$ National Institute for Communicable Disease Control and Prevention, Chinese Center for Disease Control and Prevention, Beijing, China

${ }^{3}$ Department of Immunization Program, Yiwu District Center for Disease Control and Prevention, Jinhua, China

Correspondence to

Hanqing $\mathrm{He}$;

hanqinghe@cdc.zj.cn

\section{ABSTRACT}

Objective This study aimed to investigate the nonprescription use of antibiotics for cough among children under 5 years in China.

Design A community-based cross-sectional survey. Setting A face-to-face interview based on a standard questionnaire in the community from October to December 2019.

Participants A total of 3102 children under 5 years of age were enrolled with probability proportionate to size sampling method. The children's caregivers provided the responses as their agents.

Outcome measures Cough in the past month, nonprescription use of antibiotics after cough.

Results 1211 of 3102 children were reported to have a cough in the past month. Of these, $40.2 \%(487 / 1211)$ were medicated with antibiotics, and $18.7 \%$ (91/487) of these were not prescribed. Cephalosporins were the most frequently used antibiotic $(52.8 \%)$, and community pharmacies were the main source $(53.7 \%)$. Children who coughed for $1-2$ weeks (OR 1.73, 95\% Cl 1.03 to 2.90) or 3-4 weeks (OR 2.39, 95\% $\mathrm{Cl} 1.08$ to 4.97 ), with runny nose (OR 1.86, $95 \% \mathrm{Cl} 1.13$ to 3.19 ) or those whose family annual income between $¥ 50000$ and $¥ 100000$ (OR 4.44, 95\% Cl 1.52 to 18.95) had a higher risk of non-prescription use of antibiotics than those coughing for $<1$ week, without runny nose or with family annual income $<¥ 50000$.

Conclusions Our findings indicated that a high proportion of infants and young children had been treated with antibiotics for cough, and nearly one in five of them were used without prescription. More public health campaigns and further education on the appropriate use of antibiotics are needed to ensure the rational treatment of cough in children.

\section{INTRODUCTION}

Cough is a common symptom in childhood ${ }^{1}$ and one of the most frequent reasons for consultation in daily paediatric practice. ${ }^{2}$ It has been reported that over $50 \%$ of patients with acute cough/lower respiratory tract infection are prescribed antibiotics in primary healthcare. ${ }^{3}$ However, cough can be triggered
Strengths and limitations of this study

- This is the first community-based study to investigate the prevalence, source, type, and associated factors of non-prescription antibiotic use for cough among children under 5 years in China.

- Adoption of probability proportionate to size sampling method enables higher representation of the participants.

- Well-trained interviewers fluent in the local dialect conducted a face-to-face interview.

- Potential recall and report bias may exist as we relied on caregivers' retrospective descriptions.

- Absence information about clinical diagnosis of cough constrained further investigation.

by a variety of causes, in which uncomplicated viral acute respiratory tract infections account for the majority and antibiotics are ineffective for the symptomatic relief in such cases. ${ }^{2-5}$ In contrast with prescribed antibiotics, those used without prescriptions have more potential hazards as they are often consumed without prior disease knowledge and, therefore, contribute to more antimicrobial resistance, adverse drug reactions and masking of underlying disease processes. ${ }^{67}$ Additionally, infants and young children are more vulnerable to the risks of non-prescription antibiotic use due to their immature physiology and special organic feature. ${ }^{8}$

Children under 5 years are probably more frequent users of antibiotics because of their greater burden of infectious diseases and associated mortality risks compared with older children and adults. ${ }^{9}$ A systematic analysis showed that antibiotic use for treating cough with fast or difficult breathing symptoms among children under 5 years of age was at $61.0 \%$ (95\% CI $29.1 \%$ to $84.1 \%$ ) in uppermiddle-income countries and 49.6\% $(95 \%$ CI $14.3 \%$ to $84.5 \%$ ) in lower-middle-income 
countries. ${ }^{9}$ China has the largest consumption of antibiotics in the world and has a high prevalence of nonprescription use with $36 \%$ frequency. ${ }^{6} 1011$ Although the purchase of antibiotics from retail pharmacies without a prescription has been forbidden by China's Food and Drug Administration regulations since 2004, several studies using the simulated client method (SCM) demonstrated that customers can still easily obtain antibiotics from retail shops or private pharmacies. ${ }^{12-14}$ Given the commonness and possible dangers of coughing, we put forward the hypothesis that there is a certain proportion of non-prescription antibiotics use after coughing in children under 5 years. Addressing the frequency and the corresponding factors of non-prescription use of antibiotics after the onset of cough in children is important for antibiotic abuse prevention and control. Therefore, the aim of this study was to investigate the prevalence and associated factors of non-prescription use of antibiotics in children under 5 years after cough.

\section{METHODS}

\section{Study design and participants}

We performed a cross-sectional survey in Yiwu, a countylevel city of about 2000000 people situated in the central Zhejiang Province of China. The survey was conducted from October to December 2019 and targeted children under 5 years of age.

We estimated a sample size of approximately 2305 for a conservatively assumed prevalence of non-prescription use of antibiotics after cough of $25 \%$, a permissible error of $2.5 \%$, a $5 \%$ level of significance $(\alpha)$ and a design effect of 2 .

The subjects were enrolled from all 14 townships in Yiwu using a two-stage stratified sampling procedure. First, probability proportionate to size sampling (PPS) method was used to adopt 50 clusters (villages or communities) from 14 townships (see online supplemental appendix 1). Then, a quota sampling method based on age and sex was used to select a fixed number of participants from each cluster for the questionnaire survey (see online supplemental appendix 2). Considering the potential problems of non-response, we targeted 60 individuals in each of the 50 clusters to accommodate nonparticipation.

During this study, well-trained interviewers fluent in the local dialect conducted face-to-face interviews using a standardised questionnaire. The children's parents, grandparents or other caregivers who made routine decisions on children's medication responded as their agents. Data were entered into the panel computer. We selected only one child as a participant from every household, without replacement. Impermanent residents from the sampled village (residential community) who lived in Yiwu for less than 6 months were excluded. In China, the permanent population refers to the residents living in survey place for more than 6 months. Children who had a cough in the month prior to the study were included in the final analysis of non-prescription use of antibiotics.

\section{Patient and public involvement}

No patient or member of the general public was involved in the design or planning of the study, the selection of outcome measures or the conduct of data collection.

\section{Study questionnaire}

We used a 30-item questionnaire to access the cough status and non-prescription antibiotics use behaviour of the participants (see Supplemental online supplemental appendix 3). The questionnaire was further revised after discussion and revision by the project team experts and on-site preinvestigation before it was officially used. Furthermore, logical verification was carried out in the design to avoid filling errors and missing information. The questionnaire consisted of three parts. The first part collected basic information including age, sex, ethnic group of children, occupation, educational level and annual family income of parents (caregivers). The second part covered the history of cough, including the time of onset (during the past month), the cough duration, cough characteristics, accompanying symptoms, and health-seeking behaviours. Health-seeking behaviours included whether they went to a doctor because of the last cough, which health facilities they chose for treatment, and whether the antibiotics were administered to the children after the onset of the cough. If respondents reported antibiotic administration, the source and type would be asked in detail with multiple responses. The third part included the knowledge of antibiotics, measured by nine questions related to their rational use. Each question was answered with a 5-point Likert-type scale (strongly disagree, disagree, uncertain, agree and strongly agree).

\section{Definitions of variables \\ Cough}

In the current study, cough was assessed by asking the respondents 'Has your child had a cough during the past month?' The duration of cough was categorised into less than 1 week, 1-2 weeks, 3-4 weeks and >4 weeks. Accompanying symptoms included expectoration, runny nose, fever, sore throat, dyspnoea, headache and lethargy.

\section{Non-prescription use of antibiotics}

Non-prescription use of antibiotics was defined as intermittent or continuous use of antimicrobial agents to treat self-diagnosed diseases or symptoms without medical guidance. It was assessed by asking participants the source of antibiotics (if they used any). The respondents would be regarded as using antibiotics without prescription if they reported any of the following approaches for antibiotics: self-purchase from pharmacies in the community, remainder from a previous course of treatment, storage at home or use of medicine given by friends.

\section{Other covariates}

Demographic and socioeconomic characteristics included age, sex, residential area (rural or urban) of the children, education level (primary school or below, middle/high 
school, college or above) and annual family income (<¥50 000，¥50 000 ¥99999，¥100 000 ¥199999，¥200 $000 \sim ¥ 499999$ and $\geq ¥ 500000$ ) of the children’s caregivers.

\section{Statistical analysis}

The participants' characteristics were described as frequencies and percentage for categorical variables. The source and type of antibiotics used were evaluated based on multiple response questions, and all responses were calculated as multiple response frequencies (percentages). The 5-point Likert-type scale responses to the nine questions related to the rational use of antibiotics were reclassified into three levels and depicted in the bar chart, among which 'strongly disagree' and 'disagree' were combined to 'disagree', 'strongly agree' and 'agree' were combined to 'agree', and another response was uncertain. We calculated the correct response rate for each question separately. Among these nine questions, the correct response to question3 was 'agree', and the others were 'disagree'. We used both univariate and multivariate logistic regressions to estimate the associations of demographic characteristics and features of cough with non-prescription use of antibiotics. All analyses were conducted using the R software V.3.5.1. A twosided $\mathrm{p}<0.05$ was considered statistically significant.

\section{RESULTS}

A total of 3123 caregivers of under-5-year-old children participated in the interviews. After eliminating invalid questionnaires from 21 caregivers, data from 3102 respondents were analysed (figure 1). Of the 3102 respondents, 1211 reported that their children had experienced cough during the past month. These participants were included in the final analysis of non-prescription use of antibiotics. The majority of the respondents were children's mothers

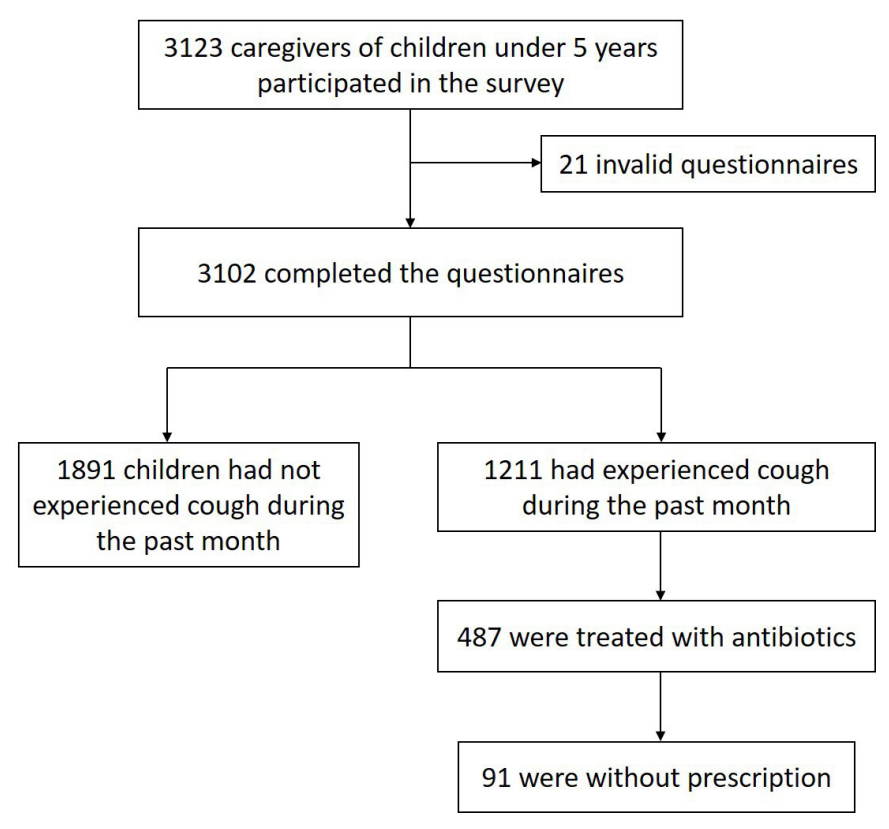

Figure 1 Flow of participants through the study.
Table 1 Characteristics of the total population and individuals with cough in the past month

\begin{tabular}{|c|c|c|}
\hline & Total popualtion & $\begin{array}{l}\text { Individuals } \\
\text { with cough } \\
\text { in the past } \\
\text { month }\end{array}$ \\
\hline Characteristics & $n=3102$ & $n=1211$ \\
\hline \multicolumn{3}{|l|}{ Child's sex } \\
\hline Male & 1740 (56.09\%) & $690(56.98 \%)$ \\
\hline Female & 1362 (43.91\%) & $521(43.02 \%)$ \\
\hline \multicolumn{3}{|c|}{ Child's age, months } \\
\hline $0-11$ & $756(24.37 \%)$ & $183(15.11 \%)$ \\
\hline $12-23$ & $623(20.08 \%)$ & 197 (16.27\%) \\
\hline 24-35 & $613(19.76 \%)$ & $236(19.49 \%)$ \\
\hline $36-47$ & 558 (17.99\%) & 307 (25.35\%) \\
\hline $48-59$ & $552(17.79 \%)$ & $288(23.78 \%)$ \\
\hline \multicolumn{3}{|l|}{ Child's residence } \\
\hline Urban & $1870(60.28 \%)$ & $714(58.96 \%)$ \\
\hline Rural & 1232 (39.72\%) & 497 (41.04\%) \\
\hline \multicolumn{3}{|c|}{ Child's cough duration, weeks } \\
\hline$<1$ & & $732(60.44 \%)$ \\
\hline $1-2$ & & $347(28.65 \%)$ \\
\hline $3-4$ & & $99(8.17 \%)$ \\
\hline$>4$ & & $33(2.73 \%)$ \\
\hline
\end{tabular}

\begin{tabular}{|c|c|c|}
\hline \multicolumn{3}{|c|}{ Caregiver's relationship with children } \\
\hline Mother & $1975(63.67 \%)$ & $794(65.57 \%)$ \\
\hline Father & $552(17.79 \%)$ & $221(18.25 \%)$ \\
\hline Grandparents & $560(18.05 \%)$ & $188(15.52 \%)$ \\
\hline Else & $15(0.48 \%)$ & $8(0.66 \%)$ \\
\hline \multicolumn{3}{|c|}{ Caregiver's education level } \\
\hline $\begin{array}{l}\text { Primary school and } \\
\text { lower }\end{array}$ & $446(14.38 \%)$ & $154(12.72 \%)$ \\
\hline Middle school & $1053(33.95 \%)$ & $356(29.40 \%)$ \\
\hline High school & $680(21.92 \%)$ & $289(23.86 \%)$ \\
\hline College and higher & $923(29.75 \%)$ & $412(34.02 \%)$ \\
\hline \multicolumn{3}{|c|}{ Family annual income (RMB) } \\
\hline$<¥ 50000$ & $356(11.48 \%)$ & $127(10.48 \%)$ \\
\hline$¥ 50$ 000 ¥99 999 & $890(28.69 \%)$ & $339(27.99 \%)$ \\
\hline$¥ 100000 \sim ¥ 199999$ & $1222(39.39 \%)$ & $476(39.31 \%)$ \\
\hline$¥ 200000 \sim ¥ 499999$ & $488(15.73 \%)$ & $212(17.51 \%)$ \\
\hline$\geq ¥ 500000$ & $120(3.87 \%)$ & 48 (3.96\%) \\
\hline Unknown & $26(0.84 \%)$ & $9(0.74 \%)$ \\
\hline
\end{tabular}

$(65.6 \%)$, followed by their fathers $(18.2 \%)$ and grandparents $(15.5 \%)$. The characteristics of the total participants and children who had cough in the last month are shown in table 1. 
A

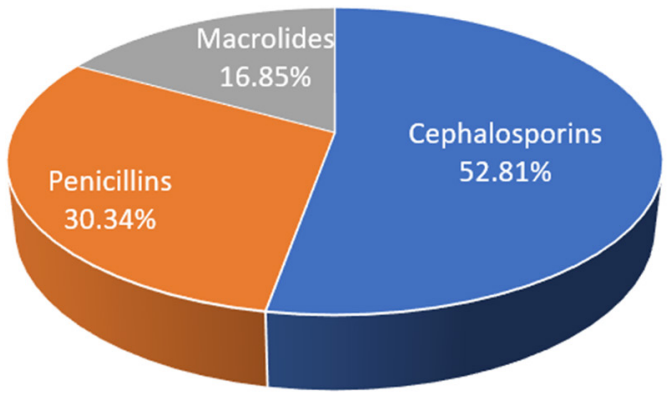

B

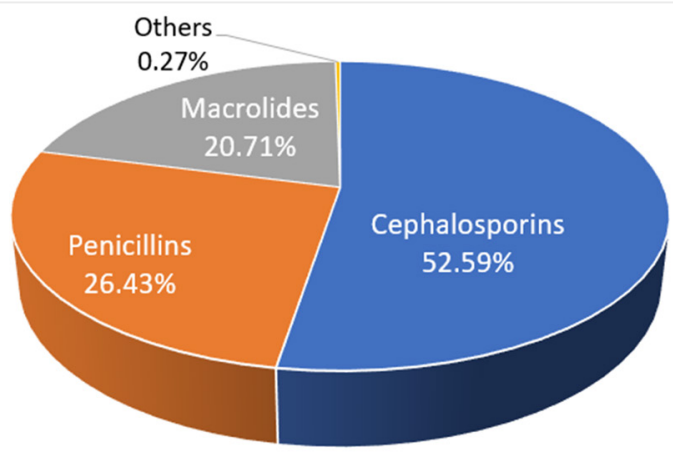

Figure 2 Types of antibiotics prescribed by doctors and those used without prescription. (A) The types of antibiotics used without a prescription. (B) The types of antibiotics prescribed by doctors. *Penicillins include amoxicillin, ampicillin, amoxicillin and clavulanate potassium. Cephalosporins include cephalexin, cefuroxime, cefminox, cefepime and other cephalosporins. Macrolides include azithromycin, erythromycin, roxithromycin and clarithromycin.

\section{Non-prescription use of antibiotics}

Among the 1211 children who had a cough in the last month, $487(40.2 \%)$ received antibiotics and 91/487 $(18.7 \%)$ received them without prescription. The most common source of the non-prescription antibiotics was community pharmacies $(53.7 \%)$, followed by storage at home $(30.5 \%)$ and leftover from a previous course of treatment $(15.7 \%)$.

Figure 2A shows the types of antibiotics used without a prescription for cough treatment. Cephalosporins were most frequently used $(52.8 \%)$, followed by penicillins (amoxicillin, ampicillin, amoxicillin-clavulanate potassium) $(30.3 \%)$ and macrolides $(16.8 \%)$. Figure 2B shows the types of antibiotics prescribed by doctors. There was no significant difference in the types of antibiotics between those prescribed by doctors and those used without prescription by the caregivers $\left(\chi^{2}=0.934\right.$, $\mathrm{p}=0.627$ ).

\section{Cognition of rational use of antibiotics}

Figure 3 shows the respondents' knowledge and attitudes toward the use of antibiotics. In total, the correct response rate to these ten questions ranged from $31.6 \%$ to $80.1 \%$. Of the respondents, $16.5 \%$ believed that antibiotics should be used as soon as possible for coughs.

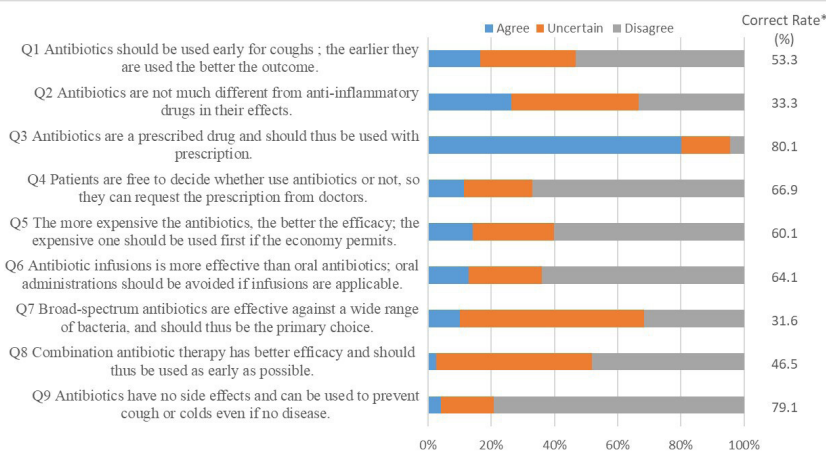

Figure 3 Knowledge of caregivers on the use of antibiotics. *Except for Q3 to which the correct answer was 'agree', the correct answers to all questions were 'disagree'.

More than $60 \%$ of respondents failed to distinguish between antibiotics and anti-inflammatory drugs. Moreover, $12.5 \%$ of respondents believed that patients have the right to decide on antibiotic use and that the patients can request the doctor to prescribe antibiotics. Further, $12.9 \%$ of them believed that the more expensive the antibiotics, the better the effect. Additionally, 11.7\% agreed that intravenous antibiotics are more effective than oral antibiotics. However, $80.1 \%$ of respondents agreed that antibiotics are a prescribed drug and should be used with prescription only.

\section{Factors associated with non-prescription use of antibiotics}

The association of sociodemographic and cough-related characteristics with non-prescription use of antibiotics after the onset of cough is presented in table 2. In univariate analyses, the caregiver's relationship with the children and annual family income were associated with nonprescription use of antibiotics. In multivariate analyses, cough duration, accompanying runny nose and family annual income were associated with non-prescription use of antibiotics. Compared with children who coughed for less than 1 week, those who coughed for 1-2 weeks (OR $1.73,95 \%$ CI 1.03 to 2.90) and 2-3 weeks (OR 2.39, 95\% CI 1.08 to 4.97 ) had a higher risk of non-prescription use of antibiotics. However, there was no significant difference between those who coughed more than 4 weeks and those who coughed for less than 1 week. As for accompanying symptoms, runny nose was associated with a higher risk of non-prescription use of antibiotics (OR 1.86, 95\% CI 1.13 to 3.19 ), while expectoration and fever were not. Further, children whose annual family income was between $¥ 50000$ and $¥ 100000$ (OR 4.44, 95\% CI 1.52 to 18.95) had a higher risk of non-prescription use of antibiotics than those whose family annual income was less than $¥ 50000$.

\section{DISCUSSION}

To the best of our knowledge, this is the first communitybased study to investigate the prevalence, source, type, and associated factors of non-prescription antibiotic 
Table 2 Univariable and multivariable analyses of the influencing factors of non-prescription use of antibiotics for cough

\begin{tabular}{|c|c|c|c|c|}
\hline & Crude OR (95\% Cl) & $P$ value & Adjusted OR (95\% Cl) & $P$ value \\
\hline \multicolumn{5}{|l|}{ Child's characteristic } \\
\hline Female sex (vs male) & 0.95 (0.61 to 1.45$)$ & 0.360 & 0.93 (0.59 to 1.46$)$ & 0.756 \\
\hline Age (every 1-year increase) & $1.02(0.87$ to 1.19$)$ & 0.815 & 0.97 (0.83 to 1.15$)$ & 0.753 \\
\hline Rural residence & $0.80(0.51$ to 1.25$)$ & 0.336 & $0.81(0.51$ to 1.28$)$ & 0.375 \\
\hline \multicolumn{5}{|l|}{ Cough duration, weeks } \\
\hline$<1$ & 1.00 (ref) & & 1.00 (ref) & \\
\hline $1-2$ & 1.57 (0.98 to 2.49$)$ & 0.059 & 1.73 (1.03 to 2.90$)$ & 0.037 \\
\hline $3-4$ & $1.86(0.89$ to 3.61$)$ & 0.079 & 2.39 (1.08 to 4.97$)$ & 0.024 \\
\hline$>4$ & 0.47 (0.03 to 2.25$)$ & 0.457 & 0.54 (0.03 to 2.85$)$ & 0.559 \\
\hline \multicolumn{5}{|l|}{ Accompanying symptoms(vs not) } \\
\hline Expectoration & 1.23 (0.79 to 1.89$)$ & 0.355 & $1.22(0.76$ to 1.94$)$ & 0.400 \\
\hline Fever & $0.62(0.32$ to 1.12$)$ & 0.140 & $0.75(0.37$ to 1.41$)$ & 0.397 \\
\hline Runny nose & 1.60 (0.99 to 2.68$)$ & 0.064 & 1.86 (1.13 to 3.19$)$ & 0.018 \\
\hline Hospital visit & 0.41 (0.26 to 0.62$)$ & $<0.01$ & 0.29 (0.18 to 0.47$)$ & $<0.01$ \\
\hline \multicolumn{5}{|l|}{ Caregiver's characteristic } \\
\hline \multicolumn{5}{|l|}{ Relationship } \\
\hline Mother & 1.00 (ref) & & 1.00 (ref) & \\
\hline Father & 0.53 (0.26 to 0.96$)$ & 0.049 & 0.59 (0.29 to 1.11$)$ & 0.125 \\
\hline Others & $0.43(0.19$ to 0.85$)$ & 0.026 & 0.64 (0.26 to 1.40$)$ & 0.295 \\
\hline \multicolumn{5}{|l|}{ Education level } \\
\hline Primary school and lower & 1.00 (ref) & & 1.00 (ref) & \\
\hline Middle school & 2.11 (0.86 to 5.19$)$ & 0.106 & 1.62 (0.65 to 4.64$)$ & 0.327 \\
\hline High school & 2.03 (0.81 to 5.12$)$ & 0.133 & 1.58 (0.59 to 4.79$)$ & 0.379 \\
\hline College and higher & 2.29 (0.94 to 5.55$)$ & 0.067 & $2.00(0.75$ to 5.97$)$ & 0.183 \\
\hline \multicolumn{5}{|l|}{ Annual income, RMB } \\
\hline$<¥ 50000$ & 1.00 (ref) & & 1.00 (ref) & \\
\hline$¥ 50$ 000 ¥99999 & 2.69 (1.43 to 5.62$)$ & 0.004 & 4.44 (1.52 to 18.95$)$ & 0.017 \\
\hline$¥ 100$ 000 ¥199999 & 2.31 (1.24 to 4.79 ) & 0.015 & 2.52 (0.84 to 10.92$)$ & 0.145 \\
\hline$¥ 200$ 000 ¥499999 & 2.19 (1.09 to 4.79$)$ & 0.036 & 1.56 (0.44 to 7.32$)$ & 0.633 \\
\hline$\geq ¥ 500000$ & $1.51(0.46$ to 4.34$)$ & 0.461 & $1.31(0.16$ to 8.66$)$ & 0.861 \\
\hline Unknown & 1.39 (0.07 to 7.69$)$ & 0.759 & 3.27 (0.15 to 31.99$)$ & 0.437 \\
\hline
\end{tabular}

use for cough among children under 5 years in China. Overall, $40.2 \%$ of the children who had a cough in the past month had been medicated with antibiotics, and $18.7 \%$ (91/487) were non-prescription use. Cephalosporins were the most frequent type of antibiotics, and community pharmacies were the main source. Children coughing for 1-4 weeks, with accompanying runny nose, or those whose annual family income between $¥ 50000$ and $¥ 100000$ had a higher risk of non prescription use of antibiotics than those coughing for $<1$ week, without runny nose, or with an annual family income $<¥ 50000$.

A national study conducted in 15 provinces in China reported that 2-week prevalence of cough was $9.39 \%$ in children aged 0-6 years old. ${ }^{15}$ In the present study, 30.9\% (1211/3102) of children had experienced a cough in the month prior to the study, and $40.2 \%$ of them had been medicated with antibiotics, which indicated a high frequency of cough and a high proportion of antibiotic use among children under 5 years. Actually, cough is a defensive physiological reflex arising from a wide range of etiologies, of which uncomplicated viral respiratory tract infections account for the majority ${ }^{16}$ and antibiotics are ineffective for etiologic or symptomatic relief in most cases. ${ }^{17} 18$ The diagnostic and treatment guidelines for cough recommend that antibiotics should not be prioritised and only given after adequate assessment. ${ }^{5} 1920$ Parental self-medication of children with antibiotics for cough may be even more dangerous and harmful. In our study, the prevalence of non-prescription antibiotic use was $7.5 \%$ (about one-fifth of antibiotic users for cough). This was relatively lower than that reported in previous studies conducted in children ${ }^{1421-24}$ and could 
be explained by the difference in populations, specific scenarios, and time interval as our study focused on children under 5 years and restricted the condition to cough within the month before the study. However, despite the lower proportion, non-prescription antibiotic use was still concerning because most caregivers lacked knowledge on rational antibiotic use. For example, more than $60 \%$ of respondents failed to distinguish between antibiotics and anti-inflammatory drugs in the present study. This indicates the need for further public health campaigns and education on the rational use of antibiotics.

The main source of non-prescribed antibiotics in this study was community pharmacies, in parallel with previous studies. ${ }^{6}$ A survey of 2423 community pharmacies from 221 districts or counties across China reported that non-prescription antibiotic dispensing (NPAD) was observed during $70.1 \%$ of adult upper respiratory tract infection (URTI) interactions. ${ }^{12}$ Another multicentre cross-sectional study conducted in three provinces reported that $73.3 \%$ of the SCM interactions generated NPAD. ${ }^{13}$ Therefore, more strict supervision should be implemented to regulate antibiotic sales. Our finding of cephalosporins as the most frequent type of selfmedicated antibiotics was consistent with a cross-sectional study using the standardised client method in Shenyang, northeastern China. Li $e t a l^{14}$ found that cephalosporins were dispensed most frequently in simulated scenarios of paediatric acute cough in community pharmacies, which indicated cephalosporins were more accessible or more likely to be provided by pharmacy staff for children and could explain our results. ${ }^{14}$ Interestingly, we found there was no significant difference in the types of antibiotics between those used without prescription by the caregivers and those prescribed by doctors in the present study. A study evaluating antibiotic use for acute URTIs in paediatric outpatient also reported that cephalosporins were used more frequently, followed by macrolides. ${ }^{25}$ It should be noted that this did not mean the caregivers' behaviours were appropriate because misuse of antibiotics was also serious in paediatric outpatient. ${ }^{25} 26$

In the present study, the duration of cough and accompanying runny nose were associated with nonprescription antibiotic use in the multivariable analysis. Children who coughed for 1 to $<4$ weeks had a higher risk of non-prescription use of antibiotics than those who coughed for less than 1 week, while those who coughed for more than 4 weeks did not. In paediatrics, cough is generally classified into three categories depending on its duration-acute cough(lasting less than 2 weeks), protracted acute(also called subacute) cough (2-4 weeks) and chronic $\operatorname{cough}$ (more than 4 weeks). ${ }^{19}$ Our results indicated that a subacute cough was a potential risk for non-prescription antibiotic use. The most common cause of subacute cough is postinfectious cough, followed by upper airway cough syndrome and cough variant asthma. ${ }^{27}$ Identification of any preceding respiratory infection and empirical treatment for postinfectious cough are important for the management of subacute cough.
Meanwhile, the OR of runny nose for non-prescription use of antibiotics approached two, which suggested runny nose could increase caregivers' anxiety and more health education merits to be enhanced. A runny nose with clear secretions is a clinical manifestation of the common cold, usually with no need for antibiotics. ${ }^{27}$

We also found that mothers were more likely to selfadministrate antibiotics to their children in the univariate analysis, which is in parallel with studies conducted in Mudanjiang. ${ }^{28}$ This may be explained by the fact that women are more sensitive to their children's physical signs. However, the association became insignificantly after adjusting for multiple factors, which indicated more studies are needed to confirm this impact. As expected, hospital visit was a protective factor for non-prescription antibiotics, since doctors' administration or explanation could alleviate caregivers' anxiety and confusion. In addition, we also found that the income bracket of $¥ 50$ 000-¥1 000000 was associated with a higher risk of nonprescription antibiotic use. The possible explanation for this phenomenon could be that caregivers, whose annual income was below this level, struggle financially and were reluctant to spend money on medicine, while those at a higher income level tended to visit a doctor for professional consultation. ${ }^{29}{ }^{30}$ Moreover, a previous study of 1596 children aged 2-18 years showed that non-prescription antibiotic use increased with children's age. ${ }^{21}$ However, we did not observe a similar association, which might be because of the narrow age range in our study.

Our study has several strengths, including the community-based population and the adoption of the PPS method for representative samples. However, our findings should be interpreted in the context of the following limitations. First, this cross-sectional study cannot exclude potential recall and report bias, even though we enquired information within the past month to reduce such biases. Second, a certain proportion of the respondents $(18.5 \%)$ were the children's grandparents, who were less educated and may have affected our results. Third, we were unable to access the diagnosis of cough in this study, which could be an unmeasured confounding variable. Forth, no patient or member of the general public were involved in the design, conduct or reporting of this study. However, we conducted an on-site pre-investigation and optimised the questionnaire to make it more understandable before it was officially used. Finally, the subjects in our study were enrolled from permanent population in only one district, and thus the generalisability of our findings to other Chinese populations may be limited. Therefore, multicentre studies with larger sample size are warranted to make a firm complement to the current study.

\section{CONCLUSIONS}

A high proportion of infants and young children had been treated with antibiotics for cough in China, and nearly one in five of these antibiotics were used without prescription. The cough duration, accompanying runny nose and 
annual family income were the influencing factors. More public health campaigns and further education on the appropriate use of antibiotics should be implemented to ensure the rational treatment of cough in children.

Acknowledgements We thank all the children and their guardians for participating in the study. We sincerely thank Dr Jianxin Yu (Chinese Center for Disease Control and Prevention) for his critical review and help in designing this study.

Contributors $\mathrm{HH}$ and ZS designed the study. YZ and XT performed the statistical analyses and wrote the manuscript. RY, $\mathrm{YZ}$ and $\mathrm{XD}$ participated in the data collection. SL and HH revised the manuscript. All authors have read and approved the final manuscript. $\mathrm{HH}$ is the guarantor of this paper.

Funding This work was supported by the National Natural Science Foundation of China (NSFC) (grant number 81973106), Beijing Municipal Natural Science Foundation (grant number 19L2060), and Zhejiang Province Project for Medical and Health Research Program (grant number 2021KY118).

Competing interests None declared.

Patient consent for publication Not applicable.

Ethics approval This study involves human participants and was approved by This study is part of the 'China Pertussis Project'. The study was approved by the institutional review board of the National Institute for Communicable Disease Control and Prevention, Chinese Centre for Disease Control and Prevention (ICDC2019010) and was conducted according to the tenets of the Declaration of Helsinki.

Provenance and peer review Not commissioned; externally peer reviewed.

Data availability statement Data are available on reasonable request.

Supplemental material This content has been supplied by the author(s). It has not been vetted by BMJ Publishing Group Limited (BMJ) and may not have been peer-reviewed. Any opinions or recommendations discussed are solely those of the author(s) and are not endorsed by BMJ. BMJ disclaims all liability and responsibility arising from any reliance placed on the content. Where the content includes any translated material, BMJ does not warrant the accuracy and reliability of the translations (including but not limited to local regulations, clinical guidelines, terminology, drug names and drug dosages), and is not responsible for any error and/or omissions arising from translation and adaptation or otherwise.

Open access This is an open access article distributed in accordance with the Creative Commons Attribution Non Commercial (CC BY-NC 4.0) license, which permits others to distribute, remix, adapt, build upon this work non-commercially, and license their derivative works on different terms, provided the original work is properly cited, appropriate credit is given, any changes made indicated, and the use is non-commercial. See: http://creativecommons.org/licenses/by-nc/4.0/.

ORCID iD

Yao Zhu http://orcid.org/0000-0001-8675-6826

\section{REFERENCES}

1 Hay AD, Heron J, Ness A, et al. The prevalence of symptoms and consultations in pre-school children in the Avon longitudinal study of parents and children (ALSPAC): a prospective cohort study. Fam Pract 2005;22:367-74.

2 Lamas A, Ruiz de Valbuena M, Máiz L. Cough in children. Arch Bronconeumol 2014;50:294-300.

3 Butler CC, Hood K, Verheij T, et al. Variation in antibiotic prescribing and its impact on recovery in patients with acute cough in primary care: prospective study in 13 countries. BMJ 2009;338:b2242.

4 Chang AB, Asher MI. A review of cough in children. J Asthma 2001;38:299-309.

5 Kelley LK, Allen PJ. Managing acute cough in children: evidencebased guidelines. Pediatr Nurs 2007;33:515-24.

6 Morgan DJ, Okeke IN, Laxminarayan R, et al. Non-prescription antimicrobial use worldwide: a systematic review. Lancet Infect Dis 2011;11:692-701.

7 Liu J. Tackling the global non-prescription use of antibiotics. Lancet Infect Dis 2020;20:169-70.
8 Klassen TP, Hartling L, Craig JC, et al. Children are not just small adults: the urgent need for high-quality trial evidence in children. PLoS Med 2008;5:e172.

9 Allwell-Brown G, Hussain-Alkhateeb L, Kitutu FE, et al. Trends in reported antibiotic use among children under 5 years of age with fever, diarrhoea, or cough with fast or difficult breathing across low-income and middle-income countries in 2005-17: a systematic analysis of 132 national surveys from 73 countries. Lancet Glob Health 2020;8:e799-807.

10 Fang Y. China should curb non-prescription use of antibiotics in the community. BMJ 2014;348:g4233.

11 Quan-Cheng K, Jian-Guo W, Xiang-Hua L, et al. Inappropriate use of antibiotics in children in China. Lancet 2016;387:1273-4.

12 Chang J, Xu S, Zhu S, et al. Assessment of non-prescription antibiotic dispensing at community pharmacies in China with simulated clients: a mixed cross-sectional and longitudinal study. Lancet Infect Dis 2019;19:1345-54.

13 Wang X, Xuan Z, Storella TH, et al. Determinants of non-prescription antibiotic dispensing in Chinese community pharmacies from socio-ecological and health system perspectives. Soc Sci Med 2020;256:113035

14 Shi L, Chang J, Liu X, et al. Dispensing antibiotics without a prescription for acute cough associated with common cold at community pharmacies in Shenyang, northeastern China: a crosssectional study. Antibiotics 2020;9. doi:10.3390/antibiotics9040163. [Epub ahead of print: 0604 2020].

15 Yu T, Zhang Y, H-s W. Two-week prevalence of illness among 0 6 years old children in 15 provinces, China. Chinese Journal of Child Health Care 2016;24:466-78.

16 Chang AB, Landau LI, Van Asperen PP, et al. Cough in children: definitions and clinical evaluation. Med J Aust 2006;184:398-403.

17 Lai K, Pan J, Chen R, et al. Epidemiology of cough in relation to China. Cough 2013;9:18.

18 Kelly LF. Pediatric cough and cold preparations. Pediatr Rev 2004;25:115-23.

19 Chang AB, Glomb WB. Guidelines for evaluating chronic cough in pediatrics: ACCP evidence-based clinical practice guidelines. Chest 2006;129:260s-83.

20 Harris AM, Hicks LA, Qaseem A, et al. Appropriate antibiotic use for acute respiratory tract infection in adults: advice for high-value care from the American College of physicians and the centers for disease control and prevention. Ann Intern Med 2016;164:425-34.

21 Bi P, Tong S, Parton KA. Family self-medication and antibiotics abuse for children and juveniles in a Chinese City. Soc Sci Med 2000;50:1445-50.

22 Chang J, Lv B, Zhu S, et al. Non-Prescription use of antibiotics among children in urban China: a cross-sectional survey of knowledge, attitudes, and practices. Expert Rev Anti Infect Ther 2018;16:163-72.

23 Torres NF, Chibi B, Middleton LE, et al. Evidence of factors influencing self-medication with antibiotics in low and middleincome countries: a systematic scoping review. Public Health 2019;168:92-101.

24 Yu M, Zhao G, Stålsby Lundborg C, et al. Knowledge, attitudes, and practices of parents in rural China on the use of antibiotics in children: a cross-sectional study. BMC Infect Dis 2014;14:112.

$25 \mathrm{Xu}$ B. Children with acute upper respiratory tract infection outpatient antibiotics use survery [Master]. Zhengzhou University, 2013.

$26 \mathrm{Xu} \mathrm{J-J,} \mathrm{Gao} \mathrm{J,} \mathrm{Guo} \mathrm{J-H,} \mathrm{et} \mathrm{al.} \mathrm{Analysis} \mathrm{of} \mathrm{antibiotic} \mathrm{treatment} \mathrm{of}$ children in a Shanghai tertiary hospital based on point prevalence surveys. BMC Infect Dis 2020;20:804

27 Asthma Workgroup, Chinese Society, Respiratory, Diseases (CSRD), Chinese Medical, Association. The Chinese national guidelines on diagnosis and management of cough (December 2010). Chin Med J 2011;124:3207-19.

28 Yang $\mathrm{H}$, zheng $\mathrm{H}$, Huang $\mathrm{H}$. Investigation and research on the cognization and application of antibiotics among the parents of preschool children. Chinese primary health care 2017;31:51-3.

$29 \mathrm{Hu} \mathrm{Y,} \mathrm{Xu} \mathrm{B,} \mathrm{Zhao} \mathrm{Q.} \mathrm{Health} \mathrm{seeking} \mathrm{behaviors} \mathrm{and} \mathrm{expenditures} \mathrm{for}$ chronic cough in outpatients of County general hospitals in northern rural Jiangsu Province. Fudan Univ J Med Sci 2006;01:39-43.

30 Jiang Q, Xu B, Jie T. Analysis of medical-seeking behavior and influencing factors of patients with chronic cough in Jiangsu rural areas supplement to volume 25 of 2003 Chinese Journal of Antituberculosis-2003. National Academic Conference of China National Antituberculosis Association Proceedings, 2003. 